\title{
Application of Sleeper Cab Thermal Management Technologies to Reduce Idle Climate Control Loads in Long-Haul Trucks
}

\author{
Jason A. Lustbader and Travis Venson \\ National Renewable Energy Lab \\ Steven Adelman, Chip Dehart and Skip Yeakel \\ Volvo Group North America \\ Manuel Sanchez Castillo \\ Aearo Technologies LLC/E-A-R Thermal Acoustic Systems
}

\begin{abstract}
In the United States, an intercity long-haul truck averages approximately $1,800 \mathrm{hrs}$ per year for idling, primarily for sleeper cab hotel loads, consuming 838 million gallons of diesel fuel across the entire long-haul fleet [1]. Including workday idling, over 2 billion gallons of fuel are used annually for truck idling [2]. The U.S. Department of Energy's National Renewable Energy Laboratory (NREL) is working on solutions to reduce idling fuel use through the CoolCab project. The objective of the CoolCab project is to work closely with industry to design efficient thermal management systems for long-haul trucks that minimize engine idling and fuel use while maintaining the cab occupant comfort.
\end{abstract}

NREL conducted an experimental test program at their Vehicle Testing and Integration Facility in collaboration with Volvo Trucks, Aearo Technologies LLC / E-A-R Thermal Acoustic Systems - a 3M company, 3M Corporation, and Dometic Environmental Corporation. The impact of thermal load reduction technologies on idle reduction systems was characterized by conducting thermal soak tests, overall heat transfer tests, and 10-hour rest period $\mathrm{A} / \mathrm{C}$ tests. Technologies evaluated included advanced insulation packages, a solar reflective film applied to the vehicle's opaque exterior surfaces, a truck featuring both film and insulation, and a battery-powered A/C system. The results demonstrated technologies that reduce heating and cooling loads for longhaul truck idling by $36 \%$ and $34 \%$, respectively, which yielded a $23 \%$ reduction in battery pack capacity of the idle reduction system.

Data was also collected for the development and validation of a CoolCalc heating, ventilating and air conditioning (HVAC) truck cab model. CoolCalc is an easy-to-use, simplified, physics-based HVAC load estimation tool developed by NREL that requires no meshing, has flexible geometry, excludes unnecessary detail, and is less time-intensive than more detailed computer-aided engineering modeling approaches [ $\underline{3}]$. This paper documents the approach, results, and conclusions from the collaborative research project.

\section{INTRODUCTION}

Heating and air conditioning are two of the primary reasons for operating the main engine in a long-haul truck during the driver rest period. In the United States, long-haul trucks (trucks that travel more than 500 miles per day) use 838 million gallons of fuel annually for rest period idling [1]. Including workday idling, over 2 billion gallons of fuel are used annually for truck idling [2]. By reducing thermal loads and improving the efficiency of climate control systems, there is a great opportunity to reduce the fuel used and emissions created by idling. Enhancing the thermal performance of cab/sleepers will enable smaller, lighter, and more cost-effective idle reduction solutions. If the fuel savings from new technologies can provide a 1- to 3-year payback period, fleet owners will be economically motivated to incorporate them. This provides a pathway to rapid 
adoption of effective thermal load and idle reduction solutions.

The U.S. Department of Energy's National Renewable Energy Laboratory (NREL) CoolCab project is researching efficient thermal management systems that maintain cab occupant comfort without the need for engine idling [4]. The CoolCab research approach is to reduce thermal loads, design for occupant thermal comfort, and maximize equipment efficiency. By working with industry partners to develop and apply commercially viable solutions that reduce fuel used for idling, both national energy security and sustainability will be improved.

\section{APPROACH}

NREL is closely collaborating with original equipment manufacturers (OEMs) and suppliers to develop and implement a strategic approach capable of producing commercially viable results to enable idle reduction systems. This strategic, three-phased approach was developed to evaluate commercially available and advanced vehicle thermal management and idle reduction technologies. The three phases, illustrated in Figure 1, are: Baseline Testing and Model Development, Thermal Load Reduction, and Idle Reduction. Each phase features applications of NREL's suite of thermal testing and analysis tools.

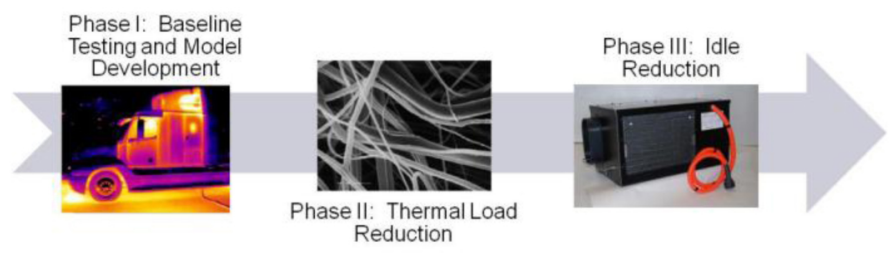

Figure 1. NREL's three-phase approach

In Phase I, Baseline Testing and Model Development, thermal data was collected on a test vehicle and on a control vehicle simultaneously. Several days of data were collected for each test procedure under varying weather conditions. This data was used to calibrate the control vehicle to represent an unmodified, baseline test vehicle. Once the control vehicle was calibrated to predict the performance of the test vehicle, validation tests were conducted. The validation days are non-calibration points used to confirm the accuracy of the control vehicle calibration. Once the accuracy of the calibration process was verified, the test vehicle was modified with technologies to reduce thermal loads. The test vehicle was then compared to the calibrated control vehicle. The baseline performance data of the test vehicle will also be used to develop and validate CoolCalc []ㅡ models for design space exploration.

In Phase II, Thermal Load Reduction, opportunities to reduce the cab/sleeper thermal loads through application of experimental benchmarking and CoolCalc parametric studies were identified. Researchers applied thermal management technologies to the truck and/or models to identify the most promising opportunities for climate control load and idle reduction.

In Phase III, Idle Reduction, the most promising of the evaluated technologies were researched further by closely collaborating with industry partners and their suppliers to design and evaluate cab thermal packages that improve thermal performance, reduce climate control loads, and enable market penetration of idle reduction systems. In this phase, vehicles were equipped with commercial and advanced cab thermal management packages coupled with an idle reduction system. NREL experimentally characterized the impact of these technologies on idle loads. Future studies will use CoolCalc analysis and vehicle simulations to characterize the reduction in idle loads and fuel use over a wide range of use and environmental conditions.

In order to experimentally characterize the impacts of the technologies being studied, thermal test procedures were conducted in each phase of the project. The test procedures used for technology evaluation were: thermal soak, overall heat transfer (UA), daytime rest period air conditioning $(\mathrm{A} / \mathrm{C})$, infiltration rate, and infrared imaging.

Thermal soak tests were conducted to evaluate the impact of technologies in an engine-off solar loading condition. This test procedure was used to characterize technology impacts on interior air temperatures in a modified truck ( $\overline{\mathrm{T}}_{\text {modified }}$ ) compared to interior air temperatures in the baseline truck

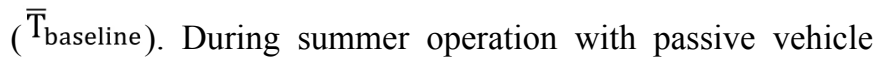
thermal load reduction technologies, the best possible steadystate performance is to reduce the interior temperature to the ambient temperature. The percent of maximum possible temperature reduction $(\beta)$ was developed to describe this maximum possible reduction in interior air temperature rise above ambient ( $\overline{\mathrm{T}}_{\text {ambient }}$ ), as described in equation 1 . A $\beta$ value of $0 \%$ means the technology under evaluation did not change the rise over ambient temperature, while a $\beta$ value of $100 \%$ means that the technology reduced the interior air temperature in the modified vehicle to equal the temperature of ambient air in the environment.

$$
\beta=\frac{\bar{T}_{\text {baseline }}-\bar{T}_{\text {modified }}}{\bar{T}_{\text {baseline }}-\bar{T}_{\text {ambient }}} \cdot 100 \%
$$

Overall heat transfer (UA) tests were conducted to quantify baseline heat loss and the impact of adding commercially available and advanced insulation. The test was conducted at night with a $1-\mathrm{kW}$ heat source in each vehicle. The sleeper curtain was closed, and the average interior sleeper air temperature ( $\overline{\mathrm{T}}_{\text {sleeper }}$ ) was calculated by averaging eight $\mathrm{k}$ - 
type thermocouples with six located in accordance with the American Trucking Association Technology Maintenance Council's recommended practice RP422A [ㅁ] . The addition of two thermocouples suspended $0.46 \mathrm{~m}$ (1.5 feet) from the sleeper headliner and oriented above the standard sleeper floor measurements improved the accuracy of the average air temperature of the sleeper compartment by better capturing the air temperature distribution, illustrated in Figure 2.

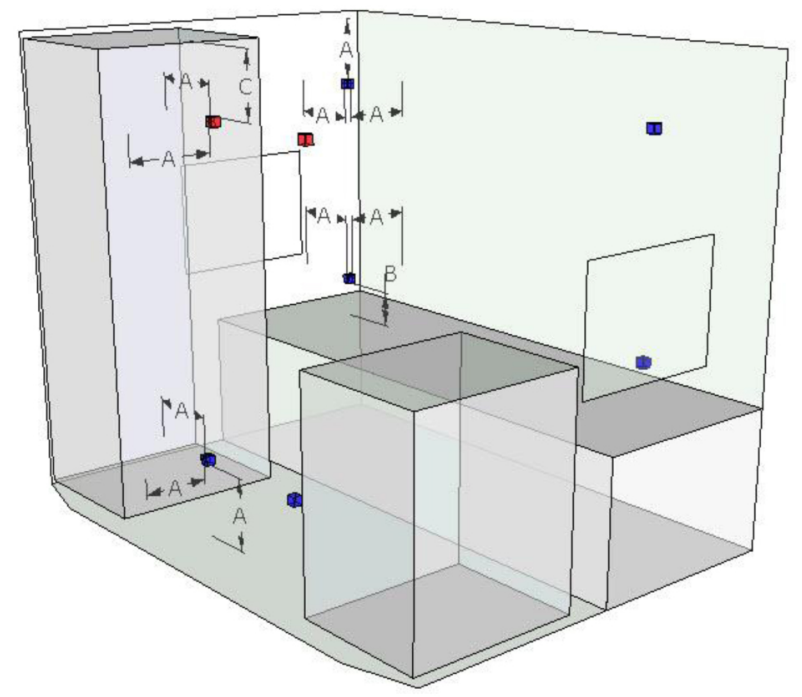

Figure 2. Sleeper thermocouple locations, dimension $A=$ 12", dimension $B=6 "$ ", $C=18^{\prime \prime}$, blue - TMC standard [5], red - NREL added

The UA value $[\mathrm{W} / \mathrm{K}]$ was calculated by measuring the heater power $(\mathrm{Q})[\mathrm{W}]$ and the temperature difference $(\Delta \mathrm{T})\left[{ }^{\circ} \mathrm{C}\right]$ between the interior air temperature $\left(\overline{\mathrm{T}}_{\text {sleeper }}\right)$ and ambient temperature ( $\overline{\mathrm{T}}_{\text {ambient }}$ ) as described in equation 2 . If the area of heat transfer in the sleeper is known, i.e. the total area of the boundaries of the sleeper living space, this test can be used to determine a truck's thermal resistance, R-value $\left[\mathrm{m}^{2}\right.$ $\mathrm{K} / \mathrm{W}]$, as described in equation 3 ,

$$
\begin{gathered}
U A=\frac{Q}{\bar{T}_{\text {sleeper }}-\bar{T}_{\text {ambient }}} \\
R_{\text {value }}=\frac{A}{U A}
\end{gathered}
$$

where $\bar{T}_{\text {sleeper }}$ is the average of all eight sleeper cab air temperature measurements and $\bar{T}_{\text {ambient }}$ is the local air temperature taken inside a naturally aspirated radiation shield between the trucks.

Infrared imaging of the test vehicle was conducted to identify heat transfer reduction opportunities in the cab/sleeper compartments by locating high heat loss paths in the cab construction. In this procedure, a $1-\mathrm{kW}$ heat source was placed inside the sleeper compartment and operated overnight to ensure radiant heat from the surrounding ground is minimized. The heat source inside the truck heats the air, inner walls, glass, and interior roof areas. Nighttime images of the front, rear, sides, and roof of the vehicle exterior were collected with a FLIR infrared imaging camera. Hot exterior surfaces, in contrast to the colder surrounding areas, identify high heat loss paths that can be selected for the placement of thermal load reduction technologies.

Infiltration tests were conducted to characterize the natural air exchange rate, or infiltration rate, between the cab interior and local environment. Air exchange rates can impact experimental results and are inputs to CoolCalc model development and validation. The test procedure was conducted by introducing a known inert gas such a sulfur hexafluoride $\left(\mathrm{SF}_{6}\right)$ in a quantity between $0-1$ part per million into the cab/sleeper compartments. A B\&K gas analyzer [6] was used to monitor the concentration of $\mathrm{SF}_{6}$ over the 3-hour test period. The decay rate of the gas concentration in the cab was then used to calculate the infiltration rate, expressed in air changer per hour $[\mathrm{ACH}]$ over the 3 -hour test period.

Rest period $\mathrm{A} / \mathrm{C}$ tests were conducted to characterize thermal management technology impacts on an electric no idle $\mathrm{A} / \mathrm{C}$ system. A 2,050 W (7,000 [BTU/hr]) Dometic electric A/C system [7] was installed in the sleeper compartment of each truck. Each A/C unit was controlled to a setpoint of $22.8^{\circ} \mathrm{C}$ $\left(73^{\circ} \mathrm{F}\right)$ and connected to a data logger that recorded current, voltage, and power. Data was logged over 24-hour periods and was reduced to represent a typical 10-hour rest period. The A/C systems operated most consistently in the daytime between the hours of 9:00 am and 7:00 pm Mountain Standard Time. This time period was used for the 10-hour daytime $\mathrm{A} / \mathrm{C}$ tests. Electrical energy consumed in watt-hours was determined by integrating the $\mathrm{A} / \mathrm{C}$ load over the 10 -hour test period.

The test program was conducted at NREL's Vehicle Testing and Integration Facility, shown in Figure 3, during the months of May through September. The facility is located in Golden, Colorado, at an elevation of 5,997 feet at latitude $39.7 \mathrm{~N}$ and longitude $105.1 \mathrm{~W}$. The experimental setup included a test vehicle, representative of current production, provided by Volvo Trucks North America and an NRELowned control vehicle. The vehicles were oriented facing south and separated by a distance of 25 feet to maximize solar loading and minimize shadowing effects. A National Instruments SCXI data acquisition system was used to record measurements at a sampling frequency of $1.0 \mathrm{~Hz}$, which was averaged over one-minute intervals. The instrumentation for each vehicle included 52 calibrated k-type thermocouples, comprised of 30 air and 22 surface locations. The thermocouples were calibrated using an isothermal bath and 
reference probe, achieving a $\mathrm{U}_{95}$ uncertainty of $\pm 0.18^{\circ} \mathrm{C}$ according to procedures given in []․ Air temperatures sensors had a double concentric cylindrical radiation shield to prevent errors due to direct solar radiation.

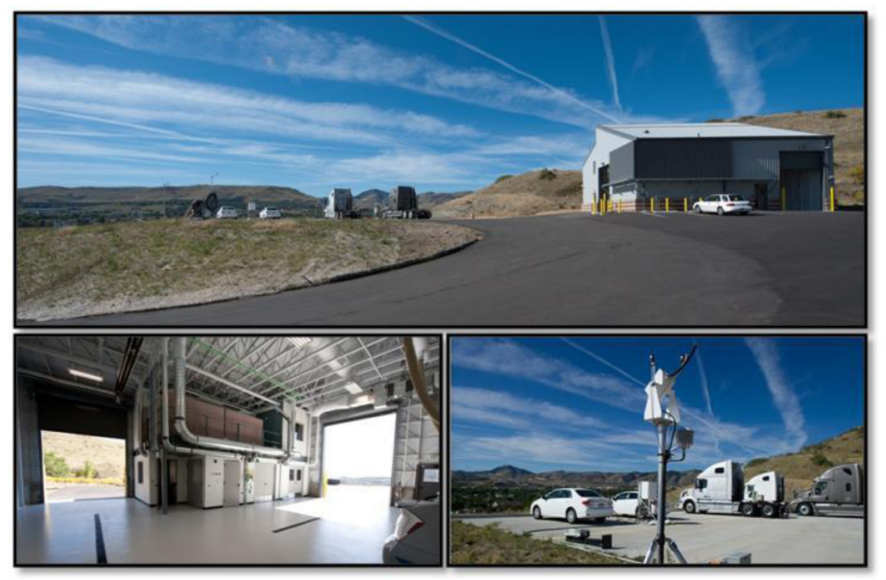

Figure 3. NREL's Vehicle Testing and Integration Facility

Weather data was collected from NREL's Solar Radiation Research Laboratory, shown in Figure 4, which features more than 150 instruments dedicated to high quality measurements of solar radiation and other meteorological parameters.

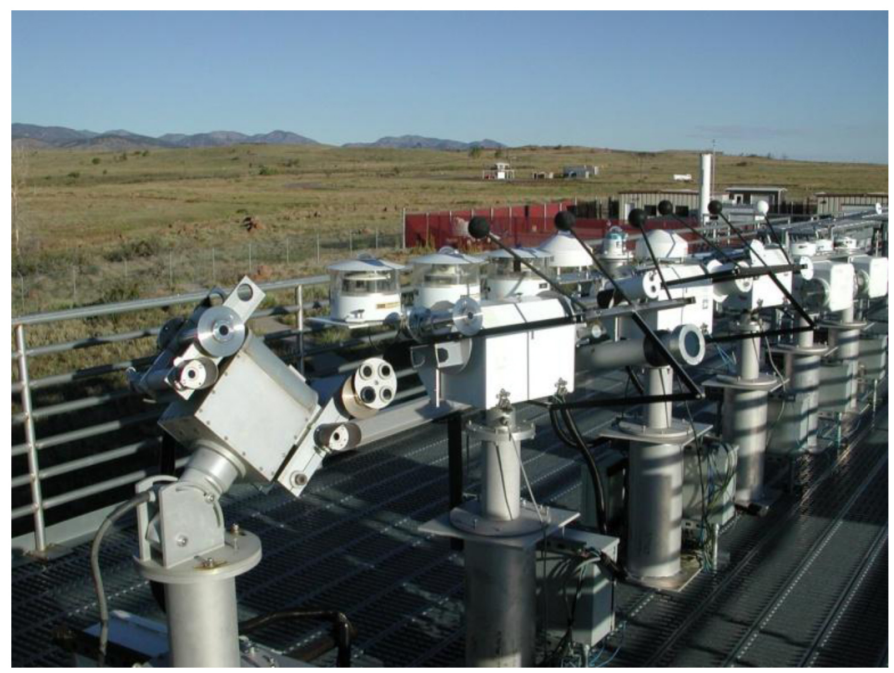

Figure 4. Solar Radiation Research Laboratory

\section{RESULTS}

\section{Phase I - Baseline Testing and Model Development}

Baseline testing was done to characterize the production performance of the trucks, calibrate the control vehicle to represent a baseline test vehicle, and collect data for the development of a CoolCalc truck model. This calibration was done using several days of unmodified vehicle baseline data.
Figure 5, illustrates the accuracy of the calibrated control truck compared to the measured test truck during baseline thermal soak tests for a validation day. In the thermal soak test configuration, the calibrated average interior air temperature in the control vehicle was on average $0.32^{\circ} \mathrm{C}$ warmer than the test vehicle on validation days.

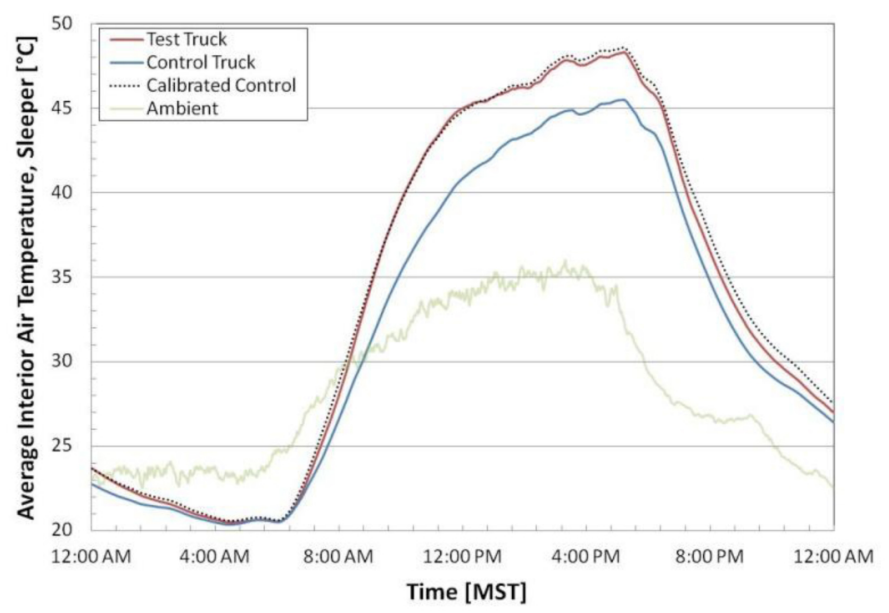

Figure 5. Baseline thermal soak results

Baseline UA testing was conducted to calibrate the overall heat transfer differences between the test and control vehicles as described in the Approach section. On average, the control truck tested $20.8 \mathrm{~W} / \mathrm{K}$ higher than the test truck. Therefore, on modified test days, the measured control truck UA value was reduced by $20.8 \mathrm{~W} / \mathrm{K}$. Two calibration validation days were used to verify that the adjusted control truck UA matched the measured test truck data. Table 1 summarizes the results of the validation days.

Table 1. Summary of Baseline UA Verification

\begin{tabular}{|lccc|}
\multicolumn{1}{|c}{ Truck } & $\begin{array}{c}\text { Check 1 } \\
\text { UA } \\
{[\mathrm{W} / \mathrm{K}]}\end{array}$ & $\begin{array}{c}\text { Check 2 } \\
\text { UA } \\
{[\mathrm{W} / \mathrm{K}]}\end{array}$ & $\begin{array}{c}\text { Mean } \\
\text { UA } \\
{[\mathrm{W} / \mathrm{K}]}\end{array}$ \\
\hline Measured Control & 70.3 & 70.2 & 70.3 \\
\hline Calibrated Control & 49.5 & 49.4 & 49.5 \\
\hline Measured Test & 48.9 & 49.8 & 49.4 \\
\hline
\end{tabular}

Baseline $\mathrm{A} / \mathrm{C}$ system test results showed that the $\mathrm{A} / \mathrm{C}$ systems did not operate overnight at the set point and weather conditions tested. Therefore, a 10-hour daytime A/C-on test period, from 9 a.m. to 7 p.m., was specified. Figure 6 illustrates the operation of the $\mathrm{A} / \mathrm{C}$ system in the control truck and the test truck. The control truck is shown in blue and the test truck in a transparent red. The overlap of the two systems can be seen as purple. Both systems toggled on and off throughout the day as the systems tried to maintain a set point of $22.8^{\circ} \mathrm{C}\left(73^{\circ} \mathrm{F}\right)$. Each system peaked at approximately 700 
$\mathrm{W}$ and had similar start and stop times. This data was used to calibrate the total energy consumed over the 10-hour rest period by the control truck $\mathrm{A} / \mathrm{C}$ system to that of the test truck $\mathrm{A} / \mathrm{C}$ system.

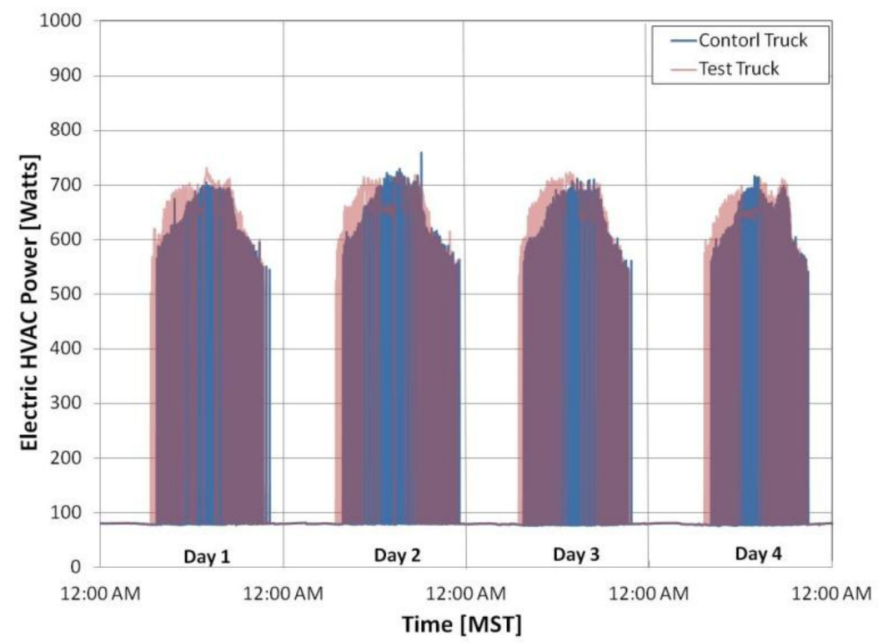

Figure 6. Baseline A/C test results

\section{Phase II - Thermal Load Reduction}

The objective of Phase II was to identify high value opportunities to reduce the thermal loads of the test truck. CoolCalc analysis, infrared imaging, and thermal testing were used to identify promising load reduction strategies. The CoolCalc tool characterized an opportunity to reduce rise over ambient by as much as $25 \%$, using a generic truck model, through application of exterior materials such as reflective paints, films, or radiant barriers to reduce the exterior absorptivity, as illustrated in Figure 7.

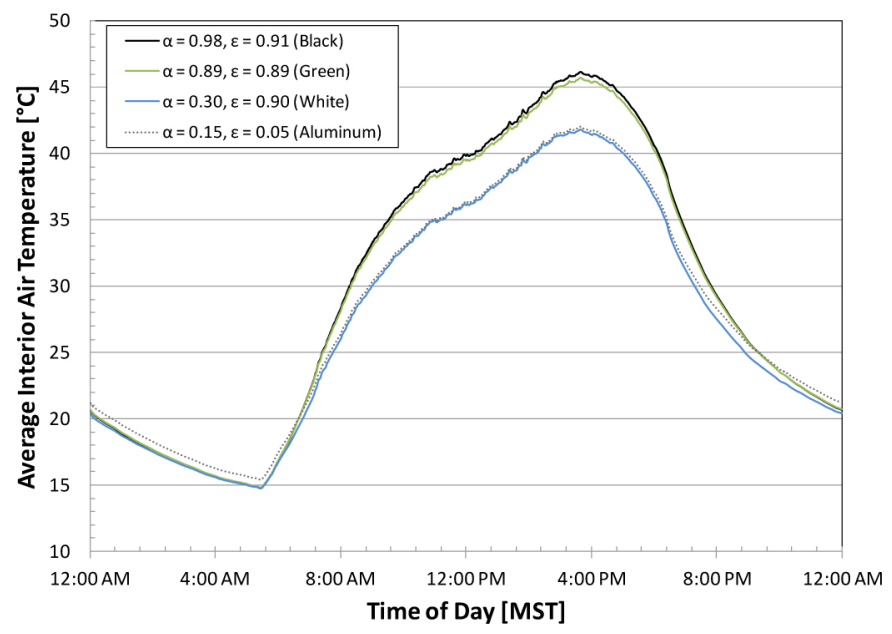

Figure 7. Absorptivity study on generic CoolCalc truck

To experimentally evaluate the opportunity for radiant barriers and to confirm the CoolCalc parametric analysis, a reflective radiant barrier was applied to a truck's exterior opaque surfaces. As illustrated in Figure 8 , a $5^{\circ} \mathrm{C}$ temperature reduction (or $\beta$ value of $32 \%$, equation 1) was achieved with the reflective barrier. Considering the differences between the generic model built in the CoolCalc tool and the test vehicle, the trends as well as magnitude agreed well. The differences between the test vehicle and the generic cab modeled in CoolCalc, include geometry, material properties, cab constructions, and window locations and glazings. Although significant differences were observed between the experiments and the parametric study, it was apparent that lowering the absorptivity of the truck exterior will improve the thermal performance of a truck in a solar loading condition.

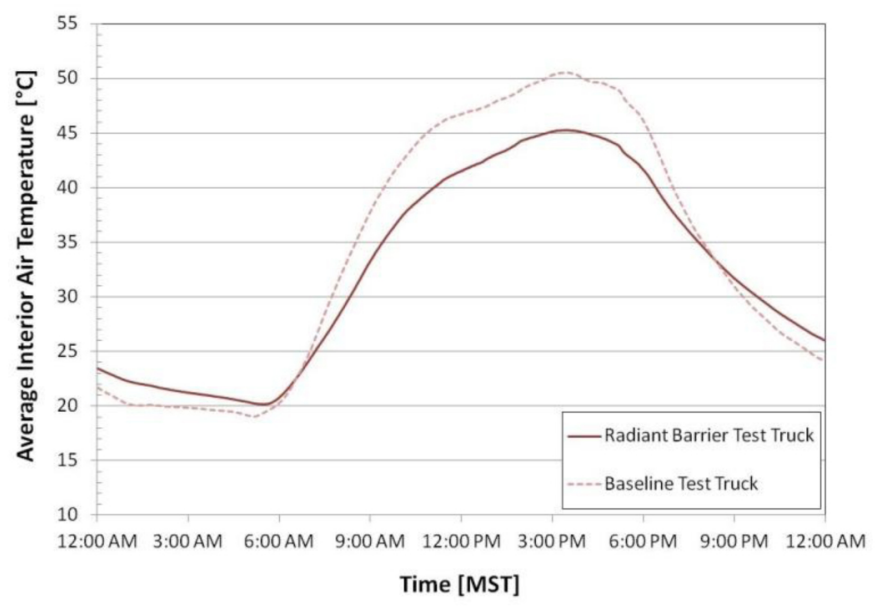

Figure 8. Radiant barrier thermal soak test results

Nighttime infrared imaging identified opportunities to enhance heat transfer performance of the vehicle. Higher temperature exterior surface areas, illustrated in Figure 9, resulted from higher heat transfer through the walls. Sidewalls, structural members in the backwall, and the roofcap presented opportunities to reduce conduction by applying commercially available and advanced insulation packages.

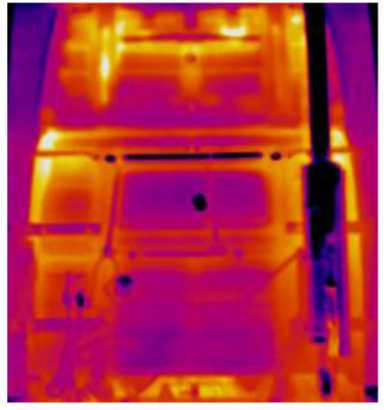

Rear View - structural members

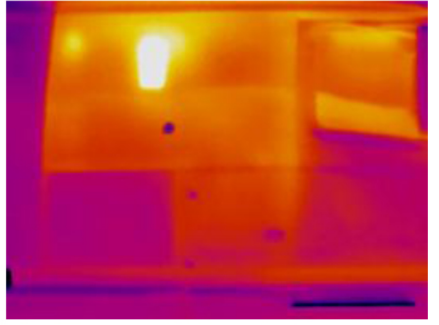

Side View - sleeper walls
Figure 9. Thermal image of sleeper back wall

To evaluate the potential benefit of improving insulation, a $16.5 \mathrm{~cm}$ (6.5 inch) thick R-19 insulation was installed in a test truck. The insulation was attached to the interior cab 
upholstery to provide a non-commercial reference, or upper limit for reduction in overall heat transfer. For the UA test, with the sleeper curtain open, the insulation resulted in a $7^{\circ} \mathrm{C}$ increase in the average interior sleeper air temperature, Figure 10 . The $7^{\circ} \mathrm{C}$ increase in temperature of the test truck over the calibrated control truck equated to a $20 \%$ reduction in overall heat transfer.

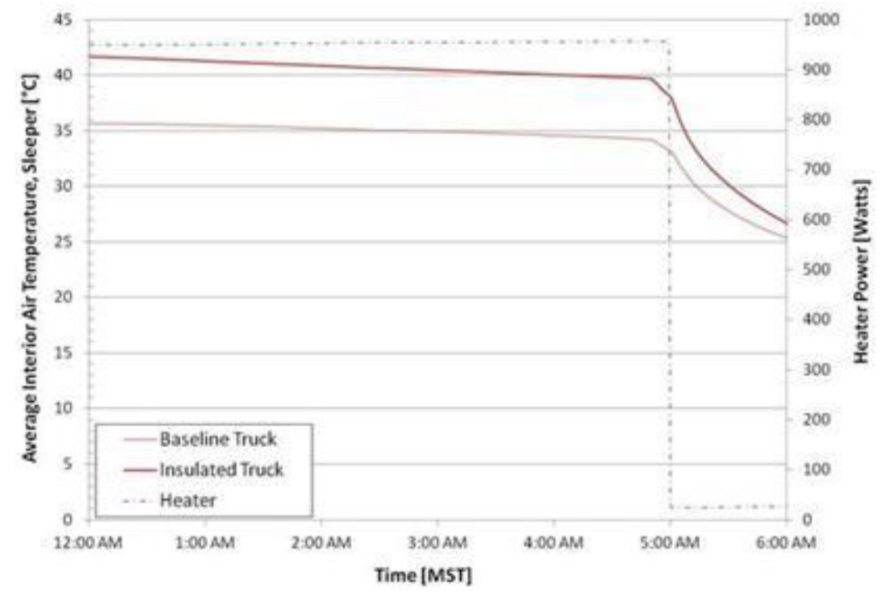

Figure 10. $R-19$ insulation $U A$ test results

\section{Phase III - Idle Reduction}

Phase III involved close collaboration with OEMs and suppliers to design commercial and advanced insulation packages for further evaluation with an on-board electric $\mathrm{A} / \mathrm{C}$ idle reduction system. NREL collaborated closely with engineers at Volvo Trucks, Aearo Technologies LLC / E-A-R Thermal Acoustic Systems - a 3M company, 3M Corporation, and Dometic Environmental Corporation. Several configurations were selected for evaluation: solar reflective film, Insulation Package I, Insulation Package I plus solar reflective film, and Insulation Package II. The baseline test data for an unmodified vehicle was compared to the modified vehicle with these different thermal load reduction packages. Thermal soak, UA, and rest period $\mathrm{A} / \mathrm{C}$ tests were conducted to determine temperature impacts, heat transfer improvements, and $\mathrm{A} / \mathrm{C}$ load reductions.

The 3M solar reflective film applied to the cab and sleeper exterior opaque surfaces resulted in a truck average interior air temperature reduction of $1.5^{\circ} \mathrm{C}$ from the baseline, a $\beta$ value of $8 \%$. This reduction was close to expectations based on modeling for a light colored vehicle. The benefit is expected to have been significantly larger if applying the technology to a darker, higher absorptivity exterior than the baseline truck's lighter color. UA tests to characterize heating reduction of the solar reflective film were not conducted because this thin film was not expected to add significantly to the wall thermal resistance. Past experiments with film resulted in immeasurable reductions in overall heat transfer, further supporting this assumption.
Insulation Package I, provided by E-A-R Thermal Acoustic Systems, was installed in the sleeper walls, floor, and roof (Figure 11). Overall heat transfer tests for Insulation Package I demonstrated an increase in interior air temperature of $5.7^{\circ} \mathrm{C}$ resulting in an overall heat transfer coefficient reduction of $13 \mathrm{~W} / \mathrm{K}$. This equates to a $26 \%$ savings on heating loads required to maintain the baseline interior air temperature. The hourly electric $\mathrm{A} / \mathrm{C}$ energy requirements for this configuration are shown in Figure 12. The hourly average $\mathrm{A} / \mathrm{C}$ load required to maintain the $22.8^{\circ} \mathrm{C}\left(73^{\circ} \mathrm{F}\right)$ set point for the calibrated control vehicle is shown in green. In this case, the calibrated control vehicle is representative of the insulation package in the baseline test vehicle. The hourly average $\mathrm{A} / \mathrm{C}$ load required for the test vehicle modified with Insulation Package I is shown in red. Therefore, visible green areas in the graph represent energy savings through application of Insulation Package I. Integrating these hourly savings shows an overall $\mathrm{A} / \mathrm{C}$ load reduction of $20 \%$ during the 10-hour daytime rest period $\mathrm{A} / \mathrm{C}$ test. Adding solar reflective film to the Insulation Package I truck improved the A/C load reduction to $22 \%$. As with the "film only" case, this improvement is expected to be higher with a darker colored vehicle. UA tests were not repeated for this test condition, since past experiments with film resulted in an immeasurable increase in wall resistance.

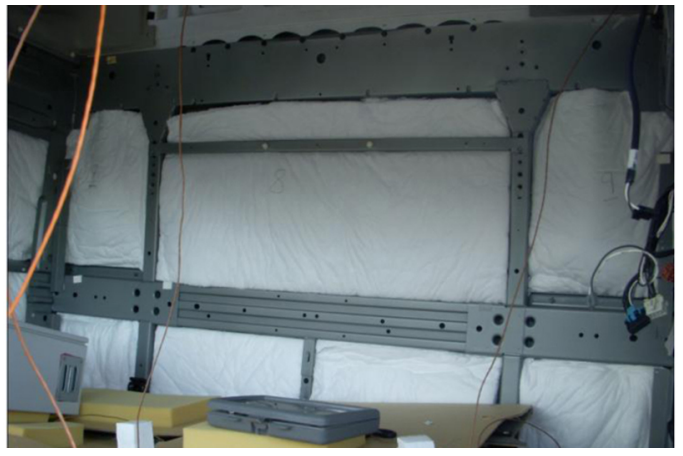

Figure 11. Insulation Package I

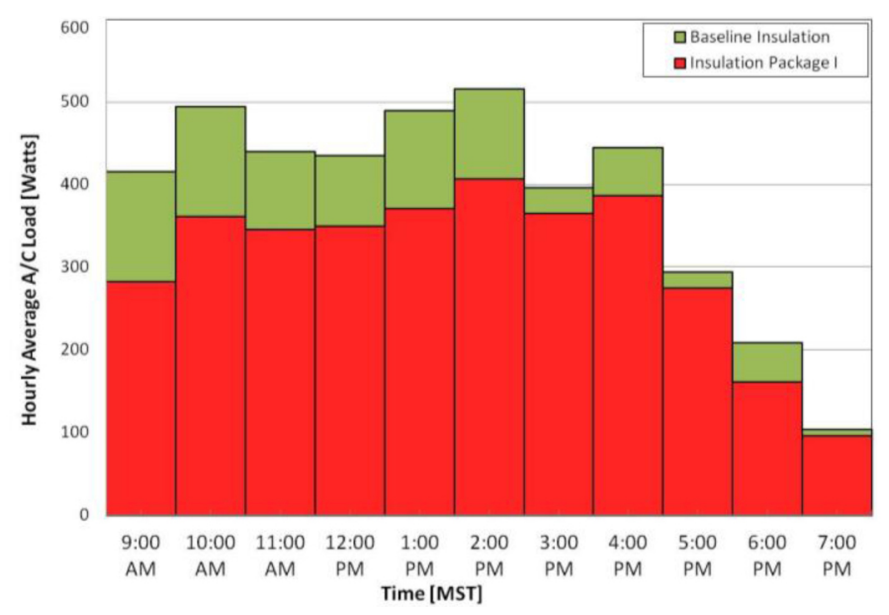

Figure 12. Insulation Package I A/C test 
Insulation Package II (Figure 13) also had insulation from EA-R Thermal Acoustic Systems installed in the walls, floor, and roof. Insulation was also added to the structural channels.

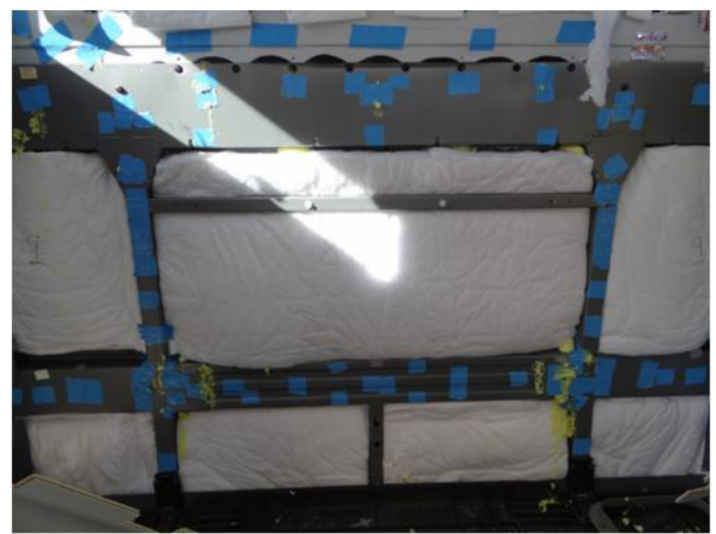

Figure 13. Insulation Package II

Insulation Package II demonstrated the most significant load reductions. Figure 14 shows the overall heat transfer test results. The insulated truck had an average interior air temperature increase of $7^{\circ} \mathrm{C}$ for a constant heat load of 965 [W]. This $23 \mathrm{~W} / \mathrm{K}$ reduction in overall heat transfer coefficient equates to a $36 \%$ savings on heating loads required to maintain the baseline interior air temperature.

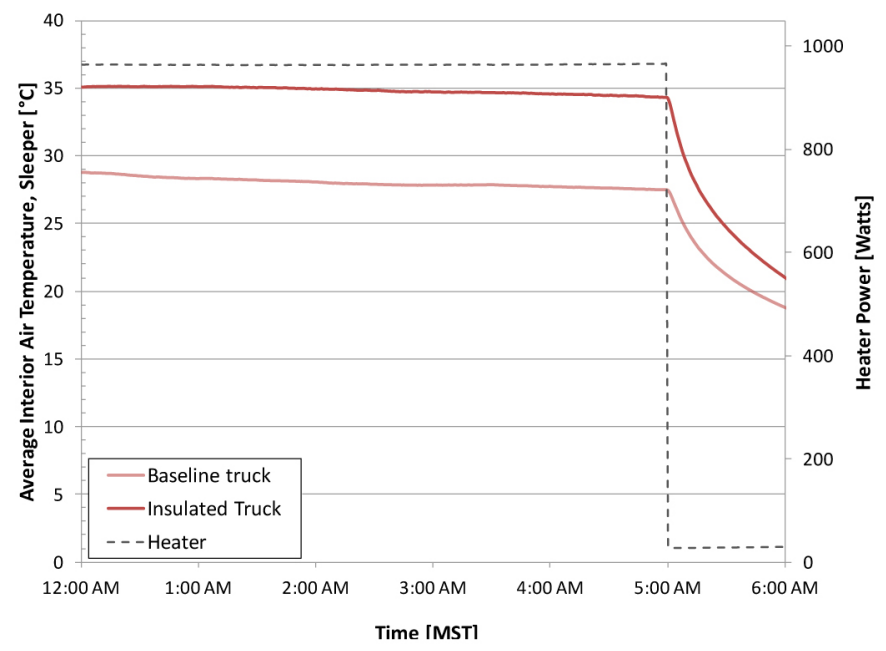

Figure 14. Overall heat transfer test (UA), Insulation Package II

The hourly daytime A/C energy consumption for the baseline vehicle compared to the vehicle modified with Insulation Package II is shown in Figure 15. Similar to Figure 14, the hourly savings are the difference between the Baseline and Insulation cases. Over the 10 -hour daytime $\mathrm{A} / \mathrm{C}$ test, a $34 \%$ reduction in cooling demand was achieved.

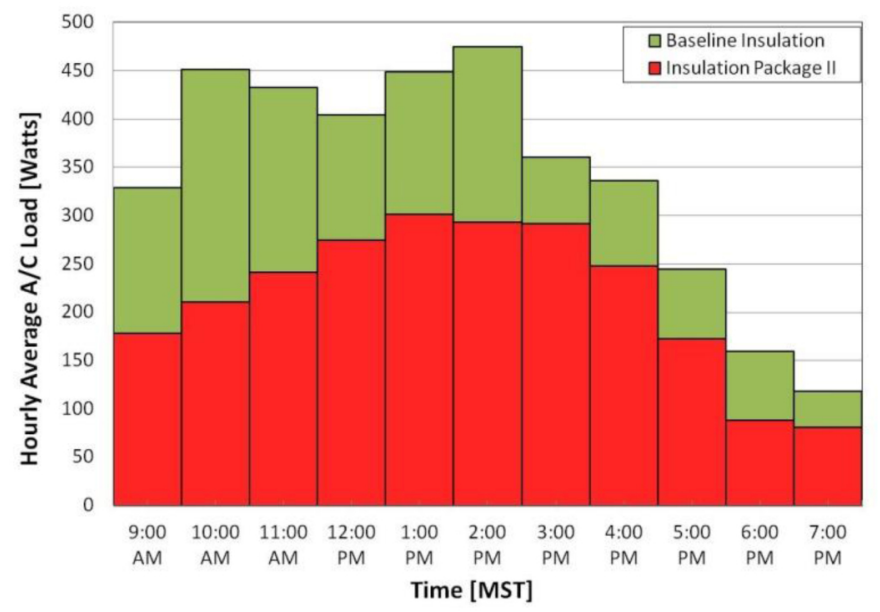

Figure 15. Insulation Package II A/C test

The Dometic electric A/C system is an idle free system that can be powered by shore power or with an onboard battery package. With a battery powered configuration, the system operates on four lead acid batteries with a capacity of approximately $1,500 \mathrm{~W}-\mathrm{hr}$ each. The total battery weight of the system is approximately $132 \mathrm{~kg}(290 \mathrm{lb})$. Table 2 summarizes the average energy savings for each test configuration over a 10-hour rest period and the associated percent reduction in $\mathrm{A} / \mathrm{C}$ capacity. These reductions can result in reductions in cost, weight, and volume of an idle reduction system. For example, a 23\% reduction in battery capacity resulting from application of Insulation Package II could equate to a mass reduction of approximately $29.5 \mathrm{~kg}$ $(65 \mathrm{lb})$ and would have an associated reduction in battery pack volume.

Table 2. Summary of Battery Energy Savings

\begin{tabular}{|lcc|}
\hline \multicolumn{1}{|c}{ Test Configuration } & $\begin{array}{c}\text { Battery } \\
\text { Energy Saved } \\
{[\mathrm{W} \text {-hr] }}\end{array}$ & $\begin{array}{c}\text { Battery Energy } \\
\text { Reduction }\end{array}$ \\
\hline Solar Reflective Film & 430 & $7 \%$ \\
\hline Insulation Package I & 900 & $15 \%$ \\
\hline $\begin{array}{l}\text { Insulation Package I } \\
\text { \& Film }\end{array}$ & 1,200 & $20 \%$ \\
\hline Insulation Package II & 1,400 & $23 \%$ \\
\hline
\end{tabular}

\section{SUMMARY/CONCLUSIONS}

Through application of commercially available and advanced vehicle thermal management technologies, heating and cooling loads required for idle reduction systems were reduced by as much as $36 \%$ and $34 \%$, respectively. An electrical energy saving of 1,400 W-hr was achieved during a 
10-hour daytime rest period while operating a batterypowered idle $\mathrm{A} / \mathrm{C}$ system under ambient conditions in Golden, Colorado. This equates to a $23 \%$ reduction in battery pack capacity for this specific auxiliary A/C system. Table 3 summarizes the impact of each configuration evaluated on climate control loads and reduction in battery capacity. Reductions in battery pack capacity lead to lower initial costs, operating costs, mass, and volume of idle reduction systems. While outside the scope of this study, additional work is planned to model the impact of these technologies over a wide range of use and operating conditions.

Table 3. Summary of Technology Impacts

\begin{tabular}{|lccc|}
\hline Test Configuration & $\begin{array}{c}\text { Heating } \\
\text { Reduction } \\
{[\% \text { of UA] }}\end{array}$ & $\begin{array}{c}\text { Cooling } \\
\text { Reduction } \\
{[\% \text { of A/C] }}\end{array}$ & $\begin{array}{c}\text { Battery } \\
\text { Energy } \\
\text { Reduction }\end{array}$ \\
\hline $\begin{array}{l}\text { Solar Reflective } \\
\text { Film }\end{array}$ & - & $8 \%$ & $7 \%$ \\
\hline $\begin{array}{l}\text { Insulation Package } \\
\text { I }\end{array}$ & $26 \%$ & $20 \%$ & $15 \%$ \\
\hline $\begin{array}{l}\text { Insulation Package } \\
\text { I \& Film }\end{array}$ & - & $22 \%$ & $20 \%$ \\
\hline $\begin{array}{l}\text { Insulation Package } \\
\text { II }\end{array}$ & $36 \%$ & $34 \%$ & $23 \%$ \\
\hline
\end{tabular}

Working closely with industry partners and applying both modeling and testing tools, NREL has shown that systematically combining vehicle thermal management and idle reduction technologies can reduce climate control loads needed for long-haul truck rest period idling. This can reduce cost, weight, and volume of idle reduction systems, improving payback period and increasing economic motivation for fleet owners and operators to consider idle reduction systems. Increasing idle reduction system effectiveness and adoption rates will help reduce the 838 million gallons used annually in the United States for longhaul truck rest period idling and potentially reduce truck operation costs.

\section{REFERENCES}

1. Stodolsky, F., Gaines, L., Vyas, A. Analysis of Technology Options to Reduce the Fuel Consumption of Idling Trucks. Argonne National Laboratory, ANL/ESD-43, June 2000.

2. Gaines, L., Vyas, A., Anderson, J., "Estimation of Fuel Use by Idling Commercial Trucks," 85th Annual Meeting of the Transportation Research Board, Washington, D.C., January 22-26, 2006, Paper No. 06-2567.

3. Lustbader, J., Rugh, J., Rister, B., and Venson, T., "CoolCalc: A Long-Haul Tuck Thermal Load Estimation Tool," SAE Technical Paper 2011-01-0656, 2011, doi: 10.4271/2011-01-0656.
4. http://www.nrel.gov/vehiclesandfuels/fleettest/ research truck thermal.html, accessed on 7/5/2012

5. "Cab Insulation Testing Methodology," RP422A-1-9, in Technology and Maintenance Council's Recommended Maintenance Practices Manual, 2010-2011 edition, Arlington, VA: American Trucking Association, $\mathrm{p}$. RP422A-1.

6. http://www.bksv.com/, accessed on 7/5/2012

7. http://www.dometictruck.com/bb-hvac.php, accessed on $7 / 5 / 2012$.

8. Dieck, R.H., Steele, W.G., Osolsobe, G. Test Uncertainty. ASME PTC 19.1-2005. New York, NY. American Society of Mechanical Engineers. 2005.

\section{CONTACT INFORMATION}

Jason A. Lustbader

National Renewable Energy Laboratory

Jason.Lustbader@nrel.gov

303-275-4443

\section{ACKNOWLEDGMENTS}

The authors would like to thank Doug Huntley at $3 \mathrm{M}$, Renewable Energy Division and Lou Siegel at Dometic Environmental Corporation for their important contributions to this project.

The authors would also like to thank Lee Slezak and David Anderson, Technology Managers for the U.S. Department of Energy's Advanced Vehicle Technology Analysis and Evaluation for sponsoring this work.

For their contributions to this project, thank you to the following NREL employees: John Rugh, Rob Farrington, Charlie King, and Matthew Jeffers.

Photo Credits: Figure 2 - Matt Jeffers, NREL; Figure 3 Dennis Schroeder, NREL; Figure 4 - Tom Stoffel, NREL; $\underline{\text { Figure } 8}, \underline{11}, \underline{12}, \underline{13}$ - Travis Venson, NREL

\section{DEFINITIONS/ABBREVIATIONS}

A/C - air conditioning

NREL - National Renewable Energy Laboratory

UA - overall heat transfer 
The Engineering Meetings Board has approved this paper for publication. It has successfully completed SAE's peer review process under the supervision of the session organizer. This process requires a minimum of three (3) reviews by industry experts. ISSN 0148-7191
Positions and opinions advanced in this paper are those of the author(s) and not necessarily those of SAE. The author is solely responsible for the content of the paper.

SAE Customer Service:

Tel: 877-606-7323 (inside USA and Canada)

Tel: 724-776-4970 (outside USA)

Fax: 724-776-0790

Email: CustomerService@sae.org

SAE Web Address: http://www.sae.org

Printed in USA 